\title{
Ateliê de desenho e Rorschach: estudo fenômeno-estrutural ${ }^{1}$
}

\author{
Jacqueline Santoantonio ${ }^{2}$ \\ Universidade Federal de São Paulo, São Paulo-SP, Brasil \\ Andrés Eduardo Aguirre Antúnez \\ Universidade de São Paulo, São Paulo-SP, Brasil
}

\begin{abstract}
Resumo: A produção de desenhos em grupo e o método de Rorschach foram utilizados ao longo do tratamento de um paciente com esquizofrenia, acompanhado em Centro de Atenção Psicossocial. O referencial proposto para a compreensão do caso é o método fenômeno-estrutural que busca acessar o modo de ser e de vivenciar a doença que afeta o paciente, a partir do que ele revela nas imagens e na linguagem. Aos desenhos de cores acromáticas e conteúdos humanos deformados, o paciente insere cores, representantes da expressão afetiva, e figuras humanas integradas, denotando disponibilidade nas relações. O Rorschach indica contato mais adequado com a realidade, dado a diminuição da distorção da percepção da forma e de figuras fantasiosas. Após diminuição da sintomatologia persecutória e isolamento social, o paciente recebeu alta. O uso desses instrumentos tem contribuído na difícil tarefa diagnóstica e no acompanhamento da evolução de pacientes, nos cuidados interdisciplinares em saúde mental.
\end{abstract}

Palavras-chave: desenho, Teste de Rorschach, fenomenologia, esquizofrenia.

\section{Workshop design and Rorschach: structural-phenomenological study}

\begin{abstract}
The production of drawings in group and the Rorschach test were used in the course of a semi-intensive psychiatric treatment of a patient with schizophrenia cared for in a Psychosocial Care Center. The structural-phenomenological method, which aims to understand individuals' way of being and experiencing a disease based on what they reveal in images and language, was used. The patient inserted colors, which represent affective expression, on drawings of achromatic colors and integrated human figures on deformed human contents showing availability in relationships. The Rorschach indicates a more appropriate contact with reality given the diminished distorted perception of fantasized form and figures. The patient was discharged after persecutory symptoms and social isolation decreased. The use of such techniques has aided the difficult task of diagnosing and monitoring changes in patients in multidisciplinary mental health care.
\end{abstract}

Keywords: drawing, Rorschach Test, phenomenology, schizophrenia.

\section{Taller para el diseño y Rorschach: estudio fenómeno-estructural}

Resumen: La producción de dibujos en grupo y el psicodiagnóstico de Rorschach de un paciente con esquizofrenia en un tratamiento psiquiátrico semi-intensivo fueron analizados. Este relato de experiencia profesional explicita la aplicación del método fenómeno-estructural, que trata de comprender la forma de ser y vivenciar del paciente y el modo como este muestra en imágenes y en el lenguaje la enfermedad que lo afecta. A los dibujos de colores acromáticos y contenidos humanos deformados, el paciente inserta colores, representantes de la expresión afectiva, y figuras humanas integradas, que muestran disponibilidad relacional. El Rorschach indica contacto más adecuado con la realidad, disminución de la distorsión perceptiva de forma y de contenidos fantasiosos. Frente la reducción de los síntomas de persecución y de aislamiento social, el paciente fue dado de alta. El uso de esas técnicas ha contribuido en la difícil tarea diagnóstica y en la evaluación de los cambios en el cuidado en salud mental multidisciplinaria.

Prof. Mello Morais, 721. CEP. 05.508-030 São Paulo-SP, Brasil. E-mail: antunez@usp.br

A arte tem sido utilizada como meio de comunicação desde a Idade da Pedra. Os desenhos feitos nas cavernas contavam os costumes, as caçadas, as relações em grupo e as crenças de nossos ancestrais. A linguagem inserida naquelas

1 Palabras clave: diseño, Test de Rorschach, fenomenologia, esquizofrenia.

Apoio: CNPq, processo 400163/2007-1. Os autores agradecem ao Centro de Atenção Psicossocial - CAPS UNIFESP e ao Prof. Dr. Michel Ternoy, vice-presidente da Société Internationale de Psychopathologie Phénoméno-structurale. Esse texto foi revisado seguindo o Acordo

2 Ortográfico da Língua Portuguesa (1990), em vigor a partir de $1^{\circ}$ de janeiro de 2009.

Endereço para correspondência:

Prof. Dr. Andrés Eduardo Aguirre Antúnez. Universidade de São Paulo. Instituto de Psicologia. Departamento de Psicologia Clínica. Av. imagens e cenas permitiu ao ser humano contextualizar hábitos e convicções e embasou uma série de concepções sobre esse modo de registrar a história que foi sendo confirmado e elaborado ao longo dos tempos. Parte da história da civilização foi contada pela análise da expressão artística de desenhos.

Os desenhos e pinturas sempre tiveram como objetivo o registro da percepção humana, para poder transmitir ao mundo a reprodução por meio de imagens que indicam facetas do pensamento e do sentimento do autor. De acordo com Safra (1999), está intrínseco na atividade de desenhar ou pintar o gesto constitutivo da imagem, e compartilhar o que foi feito oferece um reconhecimento ao que foi criado. Dessa forma, ser é fazer e dá sentido ao que foi feito.

A expressão por meio do traço e da pintura é uma das primeiras descobertas da infância. Por meio dos desenhos, a 
criança se apropria da possibilidade de reproduzir a percepção que tem do mundo e de si mesma. $\mathrm{O}$ ambiente no qual vive é responsável por muito da compreensão desses traçados em significados, em sentidos e em associações, sendo esse período decisivo para o desenvolvimento do ser humano. Caso não ocorra tal período, dificuldades e sofrimentos aparecerão.

Além de revelar ao outro os aspectos internos de quem desenha, o que foi criado apresenta, ao próprio autor, potenciais de desenvolvimento. A partir dos trabalhos de Nise da Silveira (Frayze-Pereira, 2003), muitas instituições que oferecem tratamento psiquiátrico têm adotado a expressão por meio do desenho como recurso terapêutico.

Em instituições de saúde mental de vários contextos, inclusive do Brasil, a demanda de pessoas tratadas excede a capacidade real de atendimento psicológico individual. Vasconcellos e Giglio (2007) discutem a introdução da expressão artística em contextos terapêuticos, procurando focalizar também o desenvolvimento da arteterapia com pacientes oncológicos. Os autores se referem à compreensão da arte como expressão subjetiva e à utilização de recursos artísticos no diagnóstico e na intervenção terapêutica. Concordando com os autores, esse tema tem sido pouco abordado na literatura científica nacional, apesar da importante expansão nos grandes serviços assistenciais em saúde pública. Esse campo requer maior fundamentação teórica, principalmente no contexto institucional e na adequação à realidade brasileira.

Em princípio, trabalhos em grupo são potencialmente benéficos para as pessoas tratadas nas instituições. Estas podem, por intermédio de técnicas expressivas, compartilhar seus sofrimentos, em uma mediação com terapeutas que possibilitem a busca do sentido do adoecer em suas vidas (Santoantonio \& Antúnez, 2002, 2006; Vasconcellos \& Giglio, 2007).

Em sua experiência no acompanhamento em grupo de pacientes com transtornos psiquiátricos em Atelier GraphoPicturale, Ternoy (1999a) não busca possibilidades de associação entre produção psicopatológica e criações artísticas ou não retoma questões acerca das ligações entre loucura e genialidade. Não realiza análises psicopatológicas reducionistas das obras de artes. Essa via de acesso ao outro, por meio da grafia ou pela pintura é um caminho detentor de ensinamentos insubstituíveis, graças ao poder expressivo de cada criador.

Para Ternoy (1999b), a loucura não cria um artista, mas o encontro de ambos não pode ser concebido sem marcas. Ao estudar a linguagem de pacientes com alucinações graves, por meio da análise fenômeno-estrutural do método de Rorschach, observou um mecanismo expressivo que denominou detalhismo, ou seja, uso excessivo de detalhes repetidos e perseverantes. As pinturas dos pacientes que retrataram imagens descontínuas eram de pacientes psicóticos (Ternoy, 1998).

De acordo com Ternoy (1999a), o estudo da linguagem dos pacientes psicóticos que respondem à tarefa do
Rorschach de expressar suas percepções diante de borrões de tinta abre uma via de acesso à compreensão de fenômenos essenciais, tanto em uma dimensão expressiva como relacional. A expressão é uma relação fundamental, particularmente dinâmica e viva. A expressão é uma ação humana exteriorizada e sempre é endereçada a alguém, de modo que postula, nem que seja virtualmente, um interlocutor, suscetível de apreender aquele que se expressa. A expressão mostra a coexistência, a troca e a interação entre duas pessoas.

Toda a questão da formação da subjetividade está centrada no uso da imagem, na forma sensorial que revela o estilo de ser da pessoa, em gesto criador do outro e do mundo. Além de apresentar ao terapeuta o seu existir por meio do gesto, a pessoa também se baseia na sonoridade e nas formas visuais. Uma criança vai significando suas experiências não só por meio do uso da linguagem discursiva, que ela desenvolverá na relação com a mãe, mas também pela articulação de formas estéticas e simbólicas no campo sensorial das vivências. É a criação de formas com o uso da cor, da luz, do espaço, do tempo e do tato. O ato de criar é fundamental, portanto, para que os elementos que venham a fazer parte da constituição subjetiva sejam vividos como aspectos significativos e expressivos de seu estilo pessoal. Assim, criar é existir, e os símbolos criados vão possibilitar uma articulação de maneira única na existência do indivíduo (Safra, 1999).

Amparo (2002) discute a simbolização na esquizofrenia, na perspectiva da psicopatologia fenômeno-estrutural. Seguindo a formulação de Minkowski, busca a base mental com o propósito de identificar os efeitos da Spaltung ou ruptura sobre o tempo e o espaço vividos. Utilizando estudos de casos, observou a emergência de um sentido comum na percepção dos esquizofrênicos, mesmo considerando as particularidades de cada experiência humana singular. $\mathrm{O}$ sentido comum é a constatação da ausência de determinantes formais e de movimento no Rorschach de esquizofrênicos.

A fenomenologia mais difundida em nosso país é a fenomenologia existencial francesa, tendo como representantes Jean-Paul Sartre e Merleau-Ponty. Este último reconhecia uma psicologia e uma psiquiatria fenomenológicas, tendo citado, frequentemente, em sua obra, os estudos de Minkowski e Binswanger (Veríssimo \& Furlan, 2007), com elementos que dão base para se buscar compreender, na atualidade, a dinâmica de um caso clínico de esquizofrenia a partir desta perspectiva teórica.

O objetivo desse trabalho é compreender, fenomenologicamente, a evolução clínica de um paciente com diagnóstico de esquizofrenia no início de tratamento psiquiátrico e após cinco meses de participação em um Ateliê de Desenho de Livre Expressão no Centro de Atenção Psicossocial da Universidade Federal de São Paulo - CAPS UNIFESP.

\section{Método}

Optamos pelo estudo de caso de um rapaz com 
diagnóstico de esquizofrenia, realizado de acordo com o método fenômeno-estrutural (Minkowski, 1966/1999; Minkowska, 1956/1978; Helman, 1971, 1998; Ternoy, 1997; Barthélémy, 1997, 2006).

O método fenômeno-estrutural tem sua origem na vida e na obra de Eugène Minkowski (1966/1999) e permite uma aproximação distinta e peculiar ao sofrimento vivido, possibilitando ações terapêuticas face à compreensão humana, a partir da análise fenomenológica da linguagem e das expressões. É possível observar, na livre expressão, os gestos, as necessidades, as dificuldades, as evoluções e os interesses ao longo do tempo, no processo de integração da personalidade. As intervenções clínicas permitem uma aproximação ao que é próprio de cada indivíduo em seu espaço e em seu tempo.

A atitude fenomenológica ultrapassa o plano de observação e se direciona para as características essenciais dos fenômenos que compõem a vida em sua essência. Nesse método, um caso é o suficiente para elucidar o modo de ser do paciente. Desse modo, a análise fenômeno-estrutural nos convida a precisar seus caracteres fundamentais (Helman, 1991). Em cada estrutura de personalidade, os mecanismos que a compõem singularizam e diferenciam cada sujeito. A análise fenômeno-estrutural contribui como método de análise da linguagem no Rorschach e traz em si a marca da expressão individual, do modo de ver e tomar contato com o real, com os outros e consigo mesmo. É a marca de uma maneira de se situar e de se inscrever na existência (Barthélémy, 1997). Dessa forma, a perspectiva fenômeno-estrutural procura estabelecer uma descrição rigorosa dos fenômenos e se posiciona, não no estudo de inumeráveis casos, mas na compreensão profunda de alguns casos particulares (Barthélémy, 2006).

\section{Apresentação do caso clínico}

Antonio (nome fictício), 23 anos, primeiro grau incompleto, diagnóstico de esquizofrenia paranoide, submeteu-se a tratamento psiquiátrico no CAPS UNIFESP. Seu quadro sintomático começou um ano antes de iniciar o acompanhamento no serviço, após a perda de um familiar. Apresentou comportamentos de isolamento, sorriso imotivado, alucinações auditivas e visuais e sensação de intrusão no pensamento, o que resultou em um afastamento do trabalho e do estudo. Após a melhora gradativa da crise, a ansiedade e o medo constante associados às fantasias persecutórias permaneceram.

A respeito da opção por se apresentar, neste trabalho, o método de Estudo de Caso, recorremos às considerações de Jaspers (1946/1979). Este autor afirma, em sua obra sobre psicopatologia, que a compreensão intuitiva e profunda de um caso particular ensina fenomenologicamente o que é geral para inúmeros casos. O que se apreende de um encontra-se em outros, ou seja, o foco está em identificar a visão particular do paciente, da maneira mais completa possível, reconhecendo o que pode ser compartilhado na vivência de outros.

\section{Procedimento}

No início do tratamento psiquiátrico, no Centro de Atenção Psicossocial, aplicou-se o método de Rorschach nesse paciente com esquizofrenia. Em seguida, o paciente participou de 20 sessões em grupo, onde desenhou livremente junto a outros pacientes. Após cinco meses, o método de Rorschach foi novamente administrado. Detalhes sobre os instrumentos utilizados encontram-se a seguir.

1) Método de Rorschach (Rorschach, 1921/1974), aplicado de acordo com a proposta de Minkowska (1956/1978), Helman (1971) e Ternoy (1997). A avaliação e reavaliação, por meio do Rorschach, foram administradas por dois psicólogos treinados no método fenômeno-estrutural. Minkowska (1956/1978) afirma que, diante do Rorschach, a linguagem que o sujeito apresenta não é uma linguagem convencional e automatizada, mas sim espontânea e pessoal. Também nos desenhos os participantes podem expressar suas imagens e verbalizações pessoais.

Verificamos na linguagem, palavra por palavra, como o sujeito nos apresenta sua "visão em imagens", analisando dois mecanismos essenciais presentes na estrutura da personalidade: o mecanismo de "lien" (ligação) e o mecanismo de "coupure" (corte, dissociação, ruptura), as angústias diante do "clima" sensorial provocado pelas características das figuras, a sensibilidade à cor e à afetividade, o papel do movimento na visão, seja ele humano ou animal (Helman, 1997).

É, então, observada a fenomenologia da linguagem em sua função expressiva, a qualidade do espaço e do tempo vividos pelos pacientes psiquiátricos (Minkowski, 1927/1997, 1966/1999). Em suma, é um método que observa o modo de visão, linguagem e comportamento e pode ser utilizado na análise de desenhos, no método de Rorschach e na linguagem discursiva (Helman, 1997).

2) Ateliê de Desenho de Livre Expressão (análise dos desenhos): o Ateliê de Desenho de Livre Expressão é baseado na técnica desenvolvida por Ternoy (1997), no tratamento de pacientes com transtornos psiquiátricos graves. Não se trata de oferecer ao paciente uma simples distração, ocupação, produção de arte como meio terapêutico ou catártico. O intuito não é que o paciente produza uma grande obra, mas o foco está na expressão compreendida como ato e movimento criativo.

O método se apoia na análise do fenômeno, buscando precisar suas características fundamentais. A importância de uma reflexão fenomenológica no campo da expressão é que, por meio dela, podemos entrar em contato com o outro e então observar sua visão de mundo.

Dessa forma, a expressão no Ateliê de Desenho de Livre Expressão não se reduz à coisa realizada, mas à forma de expressão de quem cria. Para Ternoy (1987), tanto o conteúdo da representação é importante como o próprio ato criativo. A expressão é compreendida em seu movimento constitutivo e dinâmico e é pela criação que a pessoa existe, se realiza e pode vir a ser. 
O Ateliê de Desenho de Livre Expressão é uma das modalidades de atendimento em grupo do Centro de Atenção Psicossocial, CAPS UNIFESP, da disciplina "Psicoterapia e Psicodinâmica", Departamento de Psiquiatria, Universidade Federal de São Paulo. Utiliza o desenho como expressão e busca favorecer o ato criativo compartilhado. Aproximadamente 200 pacientes já participaram desse grupo em dez anos de funcionamento. Semanalmente é realizada uma reunião grupal, de uma hora e meia de duração, no período da manhã, coordenada por um terapeuta e um coterapeuta. A equipe de saúde também é convidada a participar. O grupo é destinado a pacientes em tratamento intensivo e ambulatorial e conta com uma média de 15 pacientes com diversos diagnósticos psiquiátricos.

$\mathrm{O}$ material colocado à disposição é composto por lápis preto $(2 \mathrm{~B}, 4 \mathrm{~B}$ e $6 \mathrm{~B})$, lápis colorido, lápis de cera, aquarela e carvão. As pinturas ou desenhos são feitos em papel Canson de 216 x $316 \mathrm{~mm}$. Esses elementos foram escolhidos por serem considerados adequados para a confecção rápida de produções gráficas (Ternoy, 1997).

O paciente pode optar por participar do grupo ou não, e aquele que vier sabe que deverá engajar-se na atividade proposta segundo os limites estabelecidos. A sessão começa e termina na mesma hora para todos do grupo. Mesmo que o participante termine antes sua produção, ele aguardará o tempo especificado até o final da discussão. Dessa forma, a atividade estabelece um ritmo peculiar de funcionamento.

Cada sessão é composta por dois momentos: o tempo de realização das produções e o tempo de verbalização. O ritmo do trabalho proporciona o aparecimento do gesto, da imagem e, posteriormente, da verbalização, movimento que parte do gesto individual ao diálogo compartilhado entre os participantes.

No primeiro momento, com duração de cerca de 40 minutos, cada participante (inclusive terapeutas e convidados) faz seu desenho. A expressão pessoal é totalmente livre sobre o espaço da folha. O participante pode desenhar o que desejar e decidirá o destino da sua criação. Nenhuma pessoa pode interferir na folha do outro sem seu consentimento.

No segundo momento, com duração aproximada de 50 minutos, cada sujeito poderá expor ou não sua produção no quadro de cortiça para que todos observem, poderá levar seu desenho para sua casa, oferecer a alguém, ou aos terapeutas para que arquivem em uma pasta personalizada que é aberta em sua primeira participação no Ateliê.

Nessa etapa verbal, os participantes afixam seus desenhos em um quadro de cortiça. O grupo se dispõe em um semicírculo diante dos desenhos. O terapeuta, então, convida um a um a fazer comentários sobre as produções, da maneira como quiser e se quiser. Ao final, o terapeuta também expressa o que sentiu e pensou de sua própria produção e procura integrar as demais criações gráficas e os comentários de cada um. A verbalização é registrada pelo coterapeuta.

A sessão seria incompleta sem a verbalização. Nesse momento a participação também é livre, e cada um pode tomar a palavra, exprimindo-se dentro de suas possibilidades. Esses comentários podem variar de algumas palavras a explicações mais longas. As intervenções do terapeuta não visam a interpretações, mas têm o intuito de facilitar ao paciente a expressão de sua reflexão e formulações de impressões e sentimentos que motivaram suas produções.

Segundo Ternoy (1987), esse trabalho se situa no campo da metáfora mais do que da interpretação, e as pessoas reencontram nos desenhos o reflexo do vivido. A partir de suas descrições, deslizam sobre a evocação de sua própria história. Assim, os desenhos apresentam a organização e vivência no espaço e no tempo, os mecanismos de ligação e corte que dão acesso a aspectos estruturais da personalidade. Há desenhos mais sensoriais, outros racionais e também aqueles onde ambos os mecanismos aparecem. Descreveremos esses mecanismos no decorrer da análise do jovem adulto com diagnóstico de esquizofrenia.

Quanto às questões éticas, este estudo pautou-se nos cuidados preconizados para pesquisa envolvendo seres humanos. Pacientes e seus familiares foram informados, no momento da admissão, sobre o estudo e os procedimentos clínicos utilizados, garantindo-se o direito ao anonimato e sigilo em relação aos dados coletados.

\section{Resultados e Discussão}

A seguir, apresentaremos algumas vinhetas clínicas dos resultados do primeiro e segundo Rorschach e comentários essenciais de seus desenhos. Apresentaremos recortes dos resultados do Rorschach e de seus desenhos.

Seu primeiro Rorschach é marcado por comentários relacionados ao impacto ocasionado pelas imagens persecutórias - uma figura estranha, uma cara assustada, um psicopata, o predador, um monstro bravo - e pelo corte - uma furadeira entrando em uma mulher grávida. Os personagens de filmes e de desenhos animados aparecem em detrimento das figuras humanas, revelando a perda do contato vital com a realidade. As respostas de forma são em sua maioria inadequadas, e a descrição prevalece sobre a elaboração. $\mathrm{O}$ distanciamento afetivo é revelado pela ausência de cor. Os conteúdos revelam uma visão fragmentada e marcada pelo corte - partes animais, anatomias -, confirmando a ruptura e perda do contato vital com a realidade, descrita por Minkowski (1997) como característica essencial da esquizofrenia.

Nas 20 participações no Ateliê de Desenho de Livre Expressão, sua produção gráfica é realizada rapidamente, por meio de um traço veloz e esquemático com o mesmo lápis preto ou carvão. Em seus desenhos prevalece a repetição das linhas cortadas e o traçado repleto de descontinuidades que se agrupam e se transformam em figuras fortuitas onde o paciente não identifica a intenção primeira do conteúdo do desenho. Os olhos são características constantes, assim como os dentes ou mesmo a justaposição dos dois, marcando o olhar como sendo devorador, agressivo e, portanto, persecutório. 
As caricaturas deformadas e a acentuação da sexualidade misturada com as vivências de invasão também são descritas como expressão da esquizofrenia por Jaspers (1979).

Segundo Minkowska (1956/1978), o mecanismo de corte ou spaltung é a característica mais comum nos esquizofrênicos. O processo de spaltung que é seguido da perda do contato vital com a realidade é relacionado com uma alteração específica do pensamento e da afetividade, assim como nas relações com o mundo exterior.

Semelhante a um paciente esquizofrênico descrito por Helman (1971), o corte está presente no Rorschach e nos desenhos de Antonio por meio da execução que se interrompe e é retomada, sem uma finalidade: tudo parece vago no tempo. Somente uma figura humana é desenhada, e é uma pessoa inacabada e cortada em suas extremidades. Ao longo das sessões, acaba por fazer cenas integradas, porém os personagens são figuras humanas imaginárias imprimindo à cena uma expressão irreal do humano. Na última sessão, a cor vermelha aparece discretamente.

Na segunda avaliação por meio do método de Rorschach, após cinco meses de participação no Ateliê de Pintura, embora sejam evidenciadas respostas de perseguidores abelha com garras, um super-herói que se confunde com um monstro, com cara de monstro -, as figuras humanas começam a aparecer. Vê um homem que se parece com um amigo e um casal tentando se beijar, respostas que revelam uma melhoria na disponibilidade de relação com os que o rodeiam. Ocorre diminuição da distorção da forma, mas a imagem deformada às vezes se sobrepõe e vê uma criança defeituosa na prancha X. As figuras fantasiosas também diminuem, o que indica um contato mais adequado com a realidade.

O tratamento e a evolução psiquiátrica mostraram que, após seis meses, o paciente melhorou significativamente sua sintomatologia persecutória e as alterações do pensamento, de modo a não apresentar mais os risos imotivados, tampouco as alucinações auditivas, visuais e a intrusão de ideias estranhas no pensamento. Antonio começou a questionar a pertinência dessas vivências anteriores. Esses dados revelaram maior senso crítico e, portanto, melhor contato com a realidade. Observou-se, no comportamento, uma diminuição do isolamento social e dos pensamentos persecutórios, de modo que participou da maioria dos grupos terapêuticos oferecidos no CAPS UNIFESP e ampliou seus relacionamentos dentro e fora do serviço, estabelecendo contatos interpessoais mais adequados, o que permitiu a Antonio expor seus trabalhos de desenho e pinturas em uma determinada praça pública. O paciente foi, então, encaminhado para tratamento ambulatorial. O contato com as pessoas no Ateliê possibilitou o resgate e o desenvolvimento de suas habilidades gráficas, facilitando o reconhecimento das possibilidades de ampliar a exposição de sua criação para além do espaço terapêutico. Antonio já realizou várias exposições de seus trabalhos, tendo recebido bons retornos e inclusive alguns prêmios. Tem vendido seus quadros, o que possibilita não só uma melhoria econômica, como, principalmente, a evolução positiva em sua autoestima.

\section{Considerações finais}

O Ateliê de Desenho de Livre Expressão é um espaço privilegiado para a descoberta de recursos e habilidades e, também, das dificuldades vivenciadas, sendo uma modalidade de atendimento em grupo que favorece a expressão da criatividade e o acompanhamento da evolução individual de cada participante. Essa modalidade de atendimento contribui, sobretudo, para o desenvolvimento dos aspectos da personalidade que não emergiram ou que não puderam ser acolhidos e traduzidos, quando foram vividos e apresentados como gesto em direção ao mundo. A interação com interlocutores, em um espaço referencial, promove a discriminação e a elaboração possível, durante a atividade, das sensações vividas que não puderam ser integradas.

Após algumas sessões, o estilo ou traço característico de cada paciente começa a ser percebido pelos participantes, e as identificações de características pessoais passam a ser evidenciadas também pelos outros pacientes. Podemos observar que alguns revelam, em conjunto com uma melhora sintomatológica, o estabelecimento de uma forma no desenho que antes não estava presente, ou mesmo o aparecimento de um significado ou sentido ao realizado. O aparecimento da cor no último desenho de Antonio exemplifica uma abertura para a expressão afetiva, o que não ocorria antes.

Dessa forma, o Ateliê de Desenho de Livre Expressão é uma modalidade pertinente no acompanhamento de pacientes com transtornos psiquiátricos graves, visto que cada sujeito é acompanhado em sua capacidade de discriminação, integração, e também nas suas deficiências e aprisionamentos. Essa modalidade de atendimento em grupo auxilia no diagnóstico e tratamento psiquiátrico, como pudemos demonstrar nesse paciente com diagnóstico de esquizofrenia paranoide.

A abordagem fenomenológica no campo da expressão favorece o acesso à visão de mundo do paciente, evidenciando suas necessidades e colaborando para o surgimento de vivências novas, em forma de ações que possibilitam o aparecimento do desconhecido que, não raras vezes, é acompanhado de um desamparo que precisa ser acolhido. Nesse sentido, G. Safra (comunicação pessoal, 2001) afirma que criar implica um convívio com a solidão absoluta. Todo gesto criativo cria instabilidade, pois a pessoa tem de se ausentar do mundo, destruir o que está nele. $\mathrm{O}$ ato criativo é um ato que desconstrói e apresenta o risco do impacto frente à consequência e responsabilidade do que foi criado. Na constituição da subjetividade, há uma profunda interligação entre a pessoa e o mundo, ou seja, o self é o acontecer de si mesmo no ambiente. A ação e o gesto são fundamentais para essa integração, assim como é essencial a interação com o interlocutor.

Criar junto a outras pessoas, como ocorre na produção de desenhos, revela uma faceta trágica da criatividade e da liberdade. O ato criativo é um ato livre que pode ser vivido como algo assustador, mas também essencialmente acolhedor. O Ateliê de Desenho de Livre Expressão oferece um espaço para o aparecimento do que é incompleto, permitindo o acesso a aspectos emocionais que não puderam ser 
desenvolvidos ou expressos de outra maneira.

$\mathrm{O}$ encontro humano facilita o surgimento do inusitado e surpreendente, favorecendo o gesto criativo (G. Safra, comunicação pessoal, 2001). O gesto criativo é mais que uma produção artística, mas uma ação no tempo e no espaço do não convencional, possibilitando vivências além do sofrimento e da dor psíquica, mas também vivências de encanto, de ilusão, de alegria, aspectos que ajudam na integração pessoal no cotidiano das relações humanas.

\section{Referências}

Amparo, D. M. (2002). A simbolização na esquizofrenia: Um estudo fenômeno-estrutural com o método de Rorschach. Tese de Doutorado não publicada, Universidade Católica de Brasília, Brasília, DF.

Barthélémy, J. M. (1997). A análise da linguagem no Rorschach segundo o método fenômeno-estrutural. Anais do Congresso da Sociedade Brasileira de Rorschach e Outros Métodos Projetivos, 1, 99-104.

Barthélémy, J. M. (2006). Importance et extension de l'approche qualitative dans la méthode phénoménostructurale en psychopathologie. Bulletin de la Société des Sciences Médicales du Grand-Duché de Luxembourg, 2, 249-264.

Frayze-Pereira, J. A. (2003). Nise da Silveira: Imagens do inconsciente entre psicologia, arte e política [Versão eletrônica]. Estudos Avançados, 17(49), 197-208. Recuperado em 15 janeiro 2009, de http://www. scielo.br/scielo.php?script $=$ sci_arttext\&pid $=$ S010340142003000300012\&lng=pt\&nrm=iso.

Helman, Z. (1971). La pousée sensori-motrice. Bruxelles: Charles Dessart. (Original publicado em 1959)

Helman, Z. (1991). A evolução do Rorschach no contexto da psicopatologia fenomenológica-estrutural. Temas, 40/41, 146-163.

Helman, Z. (1997). Psicopatologia fenômeno-estrutural e método de Rorschach: A evolução de uma corrente, seus desenvolvimentos atuais. Anais do Congresso da Sociedade Brasileira de Rorschach e Outros Métodos Projetivos, 1, 279-290.

Helman, Z. (1998). Psychopathologie phénoménostrucuturale et méthode de Rorschach: l'evolution d'un courant, ses développements actuels. Bulletin de Psychologie, 51(434), 93-99.

Jaspers, K. (1979). Psicopatologia geral: Psicologia compreensiva, explicativa e fenomenologia. Rio de Janeiro: Atheneu. (Original publicado em 1946)

Minkowska, F. (1978). Le Rorschach: A la recherche du monde des formes. France: Desclée de Brouwer. (Original publicado em 1956)

Minkowski, E. (1997). La shizophrénie: Psychopathologie des schizoïdes et des schizophrènes. France: Desclée de Brouwer. (Original publicado em 1927)

Minkowski, E. (1999). Traité de psychopathologie. Paris: Collection Les Empêcheurs de penser en rond. (Original publicado em 1966)
Rorschach, H. (1974). Psicodiagnóstico. Rio de Janeiro: Mestre Jou. (Original publicado em 1921)

Safra, G. (1999). A face estética do self. São Paulo: Unimarco.

Santoantonio, J., \& Antúnez, A. E. A. (2002). Atelier de pintura de livre expressão em hospital dia psiquiátrico [Versão Eletrônica]. Inter-Ação.com. Recuperado em 10 maio 2008, de http://www.ciec.org.br/Artigos/Revista_1/ jacqueline.pdf

Santoantonio, J., \& Antúnez, A. E. A. (2006). O uso de desenhos em grupo: Traços do humano compartilhado [Versão Eletrônica]. Inter.Ação.com. Recuperado em 03 maio 2007, de http://www.ciec.org.br/Artigos/Revista_5/ andres.pdf

Ternoy, M. (1987). L'espace pictural de groupe. Rorschach et psychopathologie phénoméno-structurale. Colloque Expression et psychopathologie, 3, 12-20.

Ternoy, M. (1997). Rorschach, rêve éveillé et expression grapho-picturale dans l'étude phénoméno-structurale des hallucinations. Tese de Doutorado não publicada, Université de Lille III, Lille, França.

Ternoy, M. (1998). Une caractéristique spécifique de la vision en images chez l'halluciné: Le détaillage. Bulletin de Psychologie, 51, 434, 135-141.

Ternoy, M. (1999a). Rorschach, psicosis y alucinaciones: Enfoque fenomeno-estructural. Psicodiagnosticar, 9(11), 34-46.

Ternoy, M. (1999b). A obra de Augustin Lesage: Pintor mediúnico: A criação de uma existência entre a invenção e repetição:EstudoPsicopatológico.SimpósioInternacional sobre Criatividade - uma busca interdisciplinar, 30-40.

Vasconcellos, E. A., \& Giglio, J. S. (2007). Introdução da arte na psicoterapia: Enfoque clínico e hospitalar. Estudos de Psicologia (Campinas), 24, 297-304. Recuperado em 15 janeiro 2009, de http://www. scielo.br/scielo.php?script $=$ sci_arttext\&pid $=\mathrm{S} 0103$ $166 X 2007000300009 \& \operatorname{lng}=$ pt\&nrm $=$ iso $>$

Veríssimo, D. S., \& Furlan, R. (2007). Entre a filosofia e a ciência: Merleau-Ponty e a psicología. Paideia (RibeirãoPreto), 331-342.

Jacqueline Santoantonio é doutora em ciências pelo Programa de Pós-graduação em Psiquiatria do Departamento de Psiquiatria e Psicologia Médica, Escola Paulista de Medicina, Universidade Federal de São Paulo.

Andrés Eduardo Aguirre Antúnez é Professor Doutor do Departamento de Psicologia Clínica do Instituto de Psicologia da Universidade de São Paulo.

Recebido: 09/09/2008

$1^{a}$ revisão: 16/01/2009

$2^{a}$ revisão: $19 / 03 / 2009$

Aceite final: 17/04/2009 